\title{
Study on the Free Volume in Polymer by Positron Annihilation Lifetime Spectroscopy (PALS)
}

\author{
Yongmin Kim*, Jungki Shin ${ }^{* *}$, Junhyun Kwon ${ }^{* * *}$ \\ Dept. of Radiological Science, Catholic University of Daegu ${ }^{*}$, Korea Research Institute of Standards and Science ${ }^{* *}$, \\ Korea Atomic Energy Research Institute ${ }^{* * *}$

\section{양전자소멸 수명시간 측정을 통한 폴리머소재의 자유부피에 관한 연구}

\author{
김용민, 신중기**, 권준현*** \\ 대구가톨릭대학교 방사선학과*, 한국표준과학연구원**, 한국원자력연구원***
}

\begin{abstract}
Positron Annihilation Lifetime Spectroscopy is a non-destructive technique to study voids and defects in solids by the measurement of gammas from electron-positron annihilation. In this study, we measured the lifetime of CR, EPDM, NBR, all of which are widely used polymer in various fields. A conventional fast-fast coincidence system in KAERI(Korea Atomic Energy Research Institute) has been used to measure the lifetime spectra, Three lifetime components were analyzed from each lifetime spectra. According to Tao-Eldrup model equation, the size and fraction of free-volume were calculated. Mean radius and free volume fraction of $\mathrm{CR}$, EPDM NBR are $0.1217 \mathrm{~nm}^{3}(1.9103 \%), 0.14780 \mathrm{~nm}^{3}(5.3147 \%), 0.1216 \mathrm{~nm}^{3}(2.6381 \%)$, respectively. Through these measurements, we identified the feasibility of the PAL system for polymer analysis.
\end{abstract}

Key Words : PALS(Positron Annihilation Lifetime Spectroscopy), Free Volume, Polymer

\section{요야}

양전자소멸법은 양전자와 전자가 만나 소멸하면서 발생하는 광자로부터 물질의 상태를 간접적으로 파악하는 실 험 방법이다. 본 연구에서는 다양한 분야에서 널리 사용되고 있는 폴리머인 $\mathrm{CR}, \mathrm{EPDM}, \mathrm{NBR}$ 에 대하여 양전자소멸 법을 통해 양전자 소멸시간을 측정하였다. 한국원자력연구원의 $\mathrm{Na}-22$ 선원을 이용한 양전자소멸시간측정장치를 통 해 양전자소멸시간의 세가지 수명과 세기를 측정하였다. 이중 세 번째 수명성분은 폴리머의 자유부피와 직접적으로 관계된다. Tao-Eldrup 모델을 이용하여 3가지 폴리머에 대한 자유부피를 측정하였다. 그 결과 $\mathrm{CR}, \mathrm{EPDM}, \mathrm{NBR}$ 의 자유부피와 상대비율은 각각 $0.1217 \mathrm{~nm}^{3}$ (1.910\%), $0.1478 \mathrm{~nm}^{3}(5.315 \%), 0.1216 \mathrm{~nm}^{3}(2.638 \%)$ 로 나타났다. 이 를 통해 양전자소멸법의 폴리머에 대한 적용성을 확인할 수 있었으며 향후 비파괴적으로 폴리머의 특성변화를 분석 하는 자료로 활용될 수 있을 것이다. 


\section{I . 서론}

\section{1. 폴리머의 양전자소멸 시간측정법}

양전자소멸측정법은 양전자가 물질내에서 전자와 상호작용하여 쌍소멸을 일으키면서 발생하는 광자의 특성을 이용하여 물질을 분석하는 방법이다. 양전자 소멸 장치를 통한 결함 측정기술 개발은 기존의 측정 장치로 측정하기 어려운 초미세 초저농도의 결함 구 조 분석에 활용될 수 있다. 양전자 소멸 장치는 물질 의 고유상태를 보전하면서, 비파괴적인 방법으로 결함 의 크기와 양에 구한되지 않고 극미세구조의 결함에 대한 정보를 얻을 수 있다는 데 큰 장점을 가진다 ${ }^{[1,2,3]}$.

방사성동위원소로부터 발생된 양전자는 물질 내에 서 주위의 전자와 만나 쌍소멸하면서 2 개의 광자를 발 생한다. 폴리머에서 이러한 과정은 Fig. 1 과 같이 4 가지 단계로 나뉠 수 있다. 이러한 과정은 쌍을 이루면서 포 지트로니움을 형성한다. 양전자스퍼(positron spur)라 불 리는 이 과정에서 양전자와 전자의 결합상태인 포지트 로니움은 이며 물질에 대한 정보를 가지고 있다. 이러 한 과정을 양전자 스퍼라 부른다. 포지트로니움은 양 전자와 전자의 결합상태로 가장 가벼운 원자로 알려져 있으며, 수소원자로부터 양성자를 양전자가 대체함으 로써 생성될 수 있다. 우선 양전자는 포지트로니움을 생성하지 않고 바로 전자와 만나 소멸하는 과정을 겪 을 수 있다. 이를 자유양전자 소멸(annihilation of free positron)이라 하며, 이 때의 양전자 탄생으로부터 소멸 되기까지의 양전자 수명은 약 $0.4 \mathrm{~ns}$ 로 알려져 있다.

양전자는 바로 소멸되지 않고 잉여전자와 결합하여 포지트로니움을 형성할 수도 있는데 이때의 포지트로 니움은 스핀의 결합상태에 따라 2가지 상태로 나뉜다. 우선 25\%의 확률로 양전자와 전자의 스핀방향이 반대 인 파라-포지트로니움(p-Ps, para-positronium) 을 형성할 수 있다. 파라 포지트로니움은 약 $0.125 \mathrm{~ns}$ 의 수명으로 고유하게(intrinsically) 소멸된다. $75 \%$ 의 확률로 생성된 양전자와 전자의 스핀방향이 같은 올소-포지트로니움 (o-Ps, ortho-positronium)은 약 $0.5 \sim 20 \mathrm{~ns}$ 경과 후에 소 멸하게 된다. 이 소멸은 픽오프(pick-off)소멸이라 불린 다 $^{[4,5,6]}$.

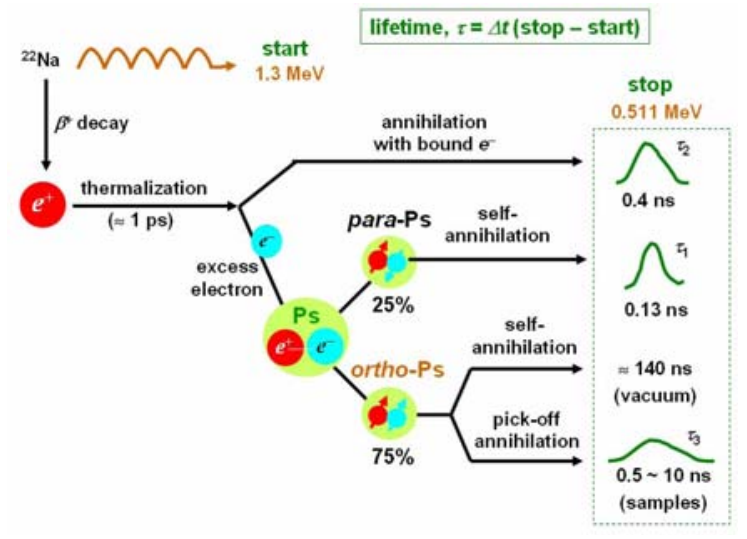

Fig. 1. Positron and Positronium lifetime components in Polymer

따라서 폴리머에서의 양전자 수명은 자유양전자, 올소, 파라-포지트로니움의 3 가지 성분으로 나타나게 된다. 이러한 수명성분은 고분자 재료의 분자수준 구 조해석에 사용된다.

\section{2. 폴리머의 자유부피(free volume)}

물질의 운동과 자유 공간(free spaces)의 관계 중요성 은 오래전부터 인지되어 왔고, 물질의 운동은 이러한 빈공간을 통해 이루어진다. 원자의 운동과 자유부피 (free volume)사이의 관계에 대한 연구는 지속되어 왔 다. 1950년 분자운동과 유리질(glassy) 및 액체(liquid) 상 태의 물리적 운동을 설명하기 위해 자유 부피(free volume) 이론이 소개되어졌다 ${ }^{[7]}$.

폴리머에서 자유부피는 전체 부피(total volume)에서 차지하고 있는 부피(occupied volume)를 빼는 것으로 표현되며 자유부피의 비율 $\left(f_{v}\right)$ 은 전체 부피 $\left(V_{t}\right)$ 에 대한 자유 부피 $\left(V_{f}\right)$ 의 비로 정의된다.

$$
f_{v}=V_{f} / V_{t}
$$

폴리머에서 정의된 자유 부피의 비율은 수 $\%$ 에서 $20 \%$ 의 범위로 보고되고 있다 ${ }^{[8]}$.

양전자 수명 측정은 Free volume의 크기와 분율 뿐 만 아니라 범위의 자세한 분포까지도 검출할 수 있으 며 PAS로 측정된 Free volume의 크기는 다른 실험결과 보다 더 이론적인 값에 더욱 가까운 값을 나타내는 것 으로 알려져 있다. 양전자 수명 성분 중 세 번째 성분 
인 pick-off annihilation의 수명은 폴리머의 자유부피와 직접적으로 연결되며 이와 관련하여 Tao-Eldrup이 제 시한 모델이 사용된다 ${ }^{[9]}$.

$$
\tau_{3}=0.5\left[1-\frac{R}{R_{0}}+\frac{\sin 2 \pi\left(R / R_{0}\right)}{2 \pi}\right]^{-1}
$$

$\tau_{3}$ 은 양전자 스펙트럼에서의 세 번째 수명성분이며 (ns) $\mathrm{R}$ 은 구를 가정한 자유부피 평균 지름, $R_{0}=R+\triangle R$ 이며 $\triangle R$ 은 경험적으로 결정된 상수이 며 Nakanishi 등에 따르면 약 $0.1656 \mathrm{~nm}$ 으로 나타났으 며 이 실험에서도 이 값을 사용하였다 ${ }^{[9,11]}$.

\section{ㅍ. 재료 및 양전자소멸수명측정}

폴리머의 자유부피를 측정하기 위하여 전선·케이블 의 피복재료, 절연재료, 자동차 부품, 각종 공업용품 등으로 널리 사용되고 있는 대표적인 고분자유기재료 들인 $\mathrm{CR}$ (Chloroprene Rubber), EPDM(ethylene propylene diene monomer), NBR(nitrile butadiene rubber)을 대상으 로 선정하였다. 양전자 수명 측정 실험을 위해 샘플들 은 $1 \times 10 \times 10 \mathrm{~mm}^{3}$ 로 구성하여 모든 양전자 선원이 샘플 내에서 소멸될 수 있도록 구성하였다.

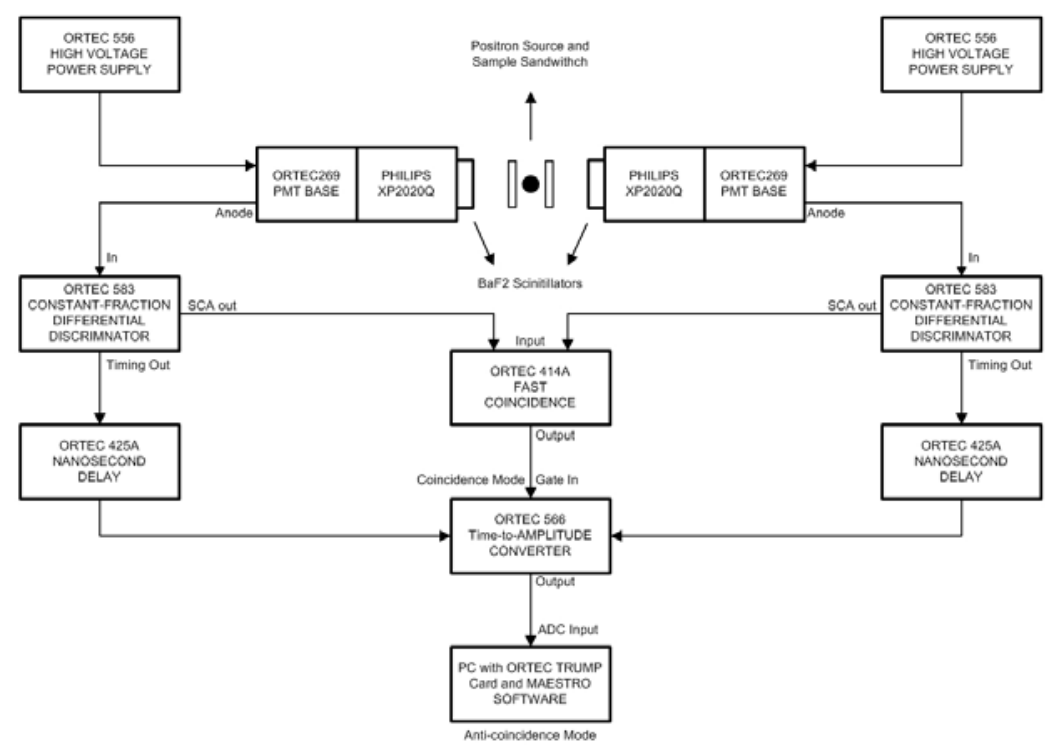

Fig. 2. The PALS system in KAERI

양전자 실험 장치는 한국원자력연구원의 양전자수 명측정시스템을 이용하였다. 한국원자력연구원의 양 전자측정시스템은 $0.511 \mathrm{MeV}$ 의 소멸광자를 동시에 측 정하기 위하여 2개의 $\mathrm{BaF}_{2}$ 섬광검출기와 $\mathrm{PMT}$, CFDD(constant fraction differential discriminators), TAC(time to amplitude converter), MCA(multi-channel analyzer), Coincidence 등으로 Fig 2. 과 같이 구성되어 있다. 양전자선원으로부터 발생된 $1.27 \mathrm{MeV}$ 의 감마선 은 섬광체에 도달하고 증폭기에서 증폭되어 펄스 신 호로 변환된다. 적분 방식 일정률 분별기(CFDD)에서 는 $1.27 \mathrm{MeV}$ 의 값에 해당되는 신호만을 판별하여 시 간-대-진폭 변환기(TAC)의 시작 신호로 보내주는 역할
을 하게 된다. 같은 과정으로 소멸방사선인 $0.511 \mathrm{MeV}$ 도 검출되어 $1.27 \mathrm{MeV}$ 와 $0.511 \mathrm{MeV}$ 의 시간차가 측정 되게 된다. 측정하는 동안 장치의 시간분해능은 $250 \mathrm{ps}$ (FWHM)로 확인되었다. 양전자 선원은 얇은 $\mathrm{Ni}$ 포일로 덮혀진 $\mathrm{Na}-22$ 가 사용되었다.

양전자수명은 $\beta(+)$ 붕괴시 방출되는 양전자와 동시 에 방출되는 $1.27 \mathrm{MeV}$ 의 감마선과 양전자가 전자와 만나 소멸되면서 발생하는 $0.511 \mathrm{MeV}$ 와의 시간간격으 로 측정되며 $\mathrm{CR}, \mathrm{EPDM}, \mathrm{NBR}$ 폴리머에 대한 양전자 수명측정 스펙트럼은 Fig. 3. 과 같이 나타난다. 스펙트 럼당 채널은 $10 \mathrm{ps}$ 로 측정되었다. 


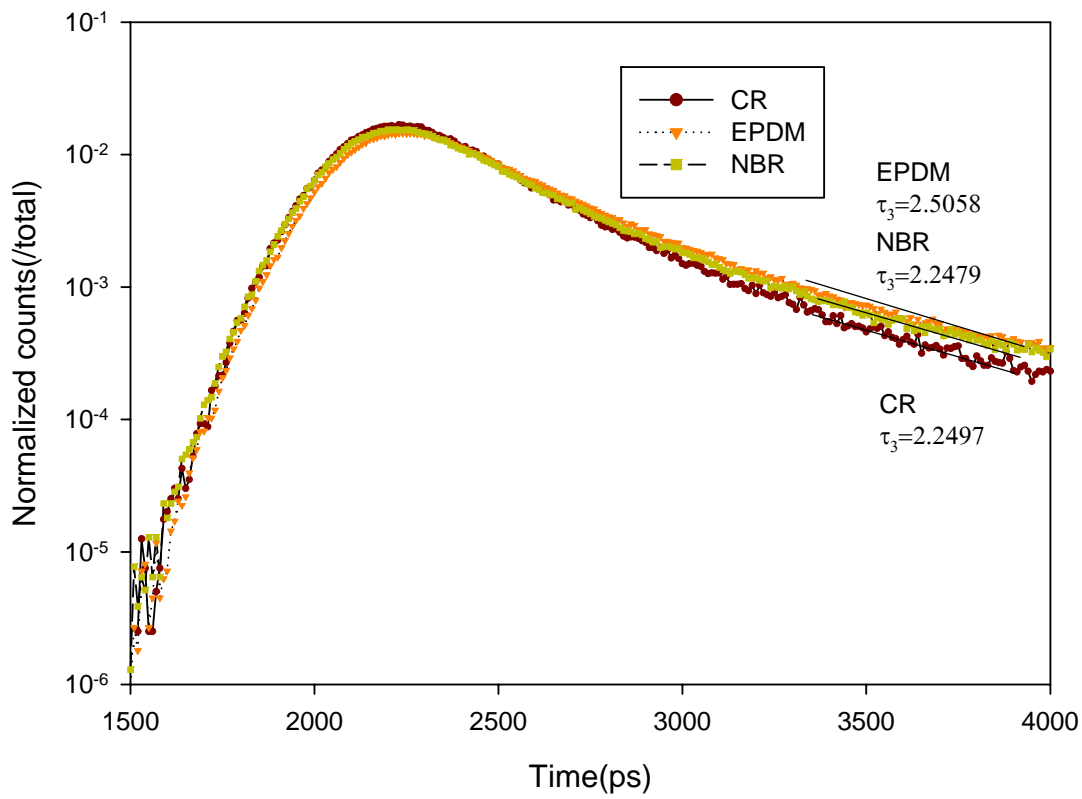

Fig. 3. Positron Annihilation Lifetime Spectra of CR, EPDM, NBR

양전자 수명 붕괴 스펙트럼 데이터는 일정한 값이 아닌 분해능 함수와 소멸 광자수에 대한 음의 지수의 적분식을 통해 수명성분을 도출할 수 있다. 스펙트럼 에서 수명성분은 곡선의 기울기에 해당하며 세 번째 성분은 뒷부분에 해당된다. 이를 Fig. 3.에 나타내었다. 양전자의 수명성분은 아래의 식 (3) 에 의해 가우시안 분포를 가정하여 다시 양전자 수명으로 분석된다.

$N(t)=\sum_{i=1}^{k+1} \frac{I_{i}}{\tau_{i}} \exp \left(-\frac{t}{\tau_{i}}\right)$

여기서 $\mathrm{N}(\mathrm{t})$ 양전자 스펙트럼 계수치이며 I는 세기 이다. 본 연구에서는 Olsen 이 개발한 PALSfit 프로그 램을 사용하여 수명성분을 도출하였다 ${ }^{[10]}$. 실험의 안정 성을 위해 실험실은 $20^{\circ} \mathrm{C}$ 에서 항온, 항습으로 유지하 였으며 샘플별로 하루 이상 측정하였다.

\section{III. 결과}

$\mathrm{CR}, \mathrm{EPDM}, \mathrm{NBR}$ 의 양전자소멸 스펙트럼을 세가지 수명성분으로 분석하였고 이중 폴리머의 자유부피와 관련된 성분인 o-Ps의 수명 $\left(\tau_{3}\right)$ 과 상대세기 $\left(I_{3}\right)$ 값의 결 과는 Table 1.과 같다.
Table 1. The 3rd Positron Annihilation Lifetime and Intensity components of $\mathrm{CR}$, EPDM, NBR.

\begin{tabular}{ccc}
$\begin{array}{c}\text { Poly } \\
\text { mer }\end{array}$ & $\begin{array}{c}\text { o-Ps Lifetime[ns] }\left(\tau_{3}\right) \\
(\text { St. d) }\end{array}$ & $\begin{array}{c}\text { Relative Intensity } I_{3}(\%) \\
\text { (St. d) }\end{array}$ \\
\hline CR & $2.2497(0.0289)$ & $8.7224(0.1345)$ \\
\hline EPOM & $2.5058(0.0137)$ & $13.5156(0.0886)$ \\
\hline NBR & $2.2479(0.0172)$ & $12.0525(0.1185)$ \\
\hline
\end{tabular}

측정된 o-Ps 수명성분으로부터 식 (2)를 통해 구를 가정한 자유부피의 평균 반지름을 구할 수 있으며 이 를 통해 자유부피의 체적을 식 (4)에 따라 계산하였다.

$$
V_{f}=\frac{4 \pi R^{3}}{3}
$$

양전자 수명 스펙트럼 분석에서 o-Ps 수명성분의 상 대적 세기 $I_{3}$ 는 o-Ps의 형성 확률에 비례하며 free volume의 양과 관계된다. 수명은 free volume의 크기와 비례하고 상대적인 세기는 free volume hole의 밀도와 관계가 있으므로 폴리머내의 free volume 비율 $\left(f_{v}\right)$ 은 다음 실험식 (5)으로 계산된다 ${ }^{[11]}$. 
$f_{v}=A \times V_{f} \times I_{3}$

여기서 $V_{f}$ 는 free volume의 체적 $\left(\AA^{3}\right)$ 이며 I는 비율 $(\%), A$ 는 보정인자로 보통 0.001 0.002 사이에 분포하 는 것으로 알려져 있다. 이 실험에서는 에폭시에서 계 산된 0.0018 을 사용하였다 ${ }^{[12]}$.

o-Ps의 수명과 세기로부터 계산한 각 폴리머의 자유 부피 평균 체적과 상대비율의 결과를 Table 2.에 나타 내었다.

Table 2. The free volume radius $\mathrm{R}$, mean free volume $\left(V_{f}\right)$, and the fraction of free volume $\left(f_{v}\right)$ in CR, EPDM, NBR.

\begin{tabular}{cccc}
\hline $\begin{array}{c}\text { Poly } \\
\text { mer }\end{array}$ & $\begin{array}{c}\text { radius }(\mathrm{R}, \AA) \\
(\text { St. d) }\end{array}$ & $\begin{array}{c}\text { mean free } \\
\text { volume } \\
\left(V_{f}, \AA^{3}\right) \\
(S t . \mathrm{d})\end{array}$ & $\begin{array}{c}\text { the fraction of } \\
\text { free volume } \\
\left(f_{v},(\%)\right) \\
(S t . \mathrm{d})\end{array}$ \\
\hline \multirow{2}{*}{ CR } & 3.074 & 121.7 & 1.9103 \\
& $(0.001)$ & $(0.1210)$ & $(0.1345)$ \\
\hline \multirow{2}{*}{ EPOM } & 3.280 & 147.8 & 5.3147 \\
& $(0.001)$ & $(0.0672)$ & $(0.002)$ \\
\hline \multirow{2}{*}{ NBR } & 3.073 & 121.6 & 2.6381 \\
& $(0.001)$ & $(0.0754)$ & $(0.003)$ \\
\hline
\end{tabular}

$\mathrm{CR}, \mathrm{EPDM}, \mathrm{NBR}$ 에 대하여 양전자소멸수명시간측 정법을 통해 구한 자유부피의 평균 크기는 $\mathrm{CR}$ 과 $\mathrm{NBR}$ 이 유사한 것으로 확인되었다. 그러나 상대적인 비율 로 $\mathrm{CR}$ 의 자유부피는 더 많은 것을 확인할 수 있었다. 측정된 폴리머에서 자유부피 비율은 기존 이론적 계 산 결과인 수 $20 \%$ 수준에 해당된다. 이것은 양전자 소멸측정법을 통해 자유부피의 비율과 평균체적을 효 율적으로 계산했음을 의미한다.

\section{$\mathrm{IV}$. 고찰}

본 연구에서는 폴리머에 대한 양전자소멸스펙트럼 측정의 타당성과 유효성을 확인하기 위하여 산업분야 에서 활발하게 사용되고 있는 폴리머인 CR. EPDM, $\mathrm{NBR}$ 에 대하여 양전자소멸시간을 측정하였다. 미국, 일본, 유럽에서는 양전자소멸분광법이 다양한 분야에 서 활발하게 활용되고 있으며 다양한 연구가 시도되 고 있다. 현재 국내에서는 양전자소멸법에 대한 관심 분야가 금속 분야에 한정되어 있으나 본 연구를 통해
고분자소재에서도 유용하게 활용할 수 있음을 확인하 였다. 본 실험을 통해 얻은 폴리머에 대한 자유부피 비율에 대한 연구 결과는 고분자 재료 연구 개발에 자 료로 활용될 수 있을 것으로 판단된다.

\section{감사의글}

이 논문은 2011년도 정부(교욱과학기술부)의 재원으 로 한국연구재단-원자력연구기반확충사업의 지원을 받아 수행된 연구임(No. 2010-0029837)

\section{참고문헌}

[1] A. Dupasquier, A.P. Mills Jr. (Eds.), Positron Spectroscopy of Solids, North Holland, Amsterdam, 1995

[2] W. Brandt, and A. Dupasquier (Eds.), Positron Solid-State Physics, North Holland, Amsterdam, 1983

[3] R. Krause-Rehberg, and H.S. Leipner, Positron Annihilation in Semiconductors, Springer, 1998

[4] Y.C. Jean, "Positron annihilation spectroscopy for chemical analysis: A novel probe for microstructural analysis of polymers", Microchemical Journal, Vol. 42, Issue 1, pp.72-102, 1990.

[5] Ole Erik Mogensen, Positron Annihilation in Chemistry, Springer-Verlag, 1994

[6] J.C. Jean, "Characterizing Free Volumes and Holes in Polyemrs by Positron Annihilation Spectroscopy", Workshop of Advances with Postrion Spectroscopy of Solids and Srufaces, Varenna, Italy, July 16-17, 1993

[7] J.D. Ferry, "Viscoelastic Properties of Polymers", John Wiley \& Son, New York, 1980

[8] A.A Bondi, "Physical Properties of Molecular Crystals, Liquids, and Crystals", ohn Wiley \& Son, New York, 1960

[9] M. Eldrup, D. Lightbody and J.N. Shherwood, Chem. Phys., 63, 51, 1981

[10] J.V. Olsen, P. Kirkegaard, N.J. Pedersen, and M. Eldrup, "PALSfit:a computer program for analysing positron lifetime spectra", Risø National Laboratory, Roskilde, Denmark, September, 2006.

[11] Y.Y. Wang, H. Nakanishi, Y.C., Jean, and T.C. Sandreczki, J. Poluy,. Sci B, 28, 1431, 1990.

[12] Y.C. Jean, Nuc. Instrum. Method B. 56/57, 615, 1991 